\title{
Chemical Cardioversion
}

National Cancer Institute

\section{Source}

National Cancer Institute. Chemical Cardioversion. NCI Thesaurus. Code C99937.

The administration of pharmacologic agents to correct abnormal heart rhythm. (ACC) 